\title{
La reorientación de flujos migratorios en la ciudad-región. El caso de la Ciudad de México en la Región Centro
}

\author{
Adrián-Guillermo Aguilar. Universidad Nacional Autónoma de México, Ciudad \\ de México, México.
}

Josefina Hernández-Lozano. Universidad Nacional Autónoma de México, Ciudad de México, México.

RESUMEN | Las ciudades-región se identifican como una nueva forma de urbanización dominante donde generalmente existe una ciudad grande junto a otros centros urbanos de diversos tamaños. En el análisis de las ciudades-región ha existido un marcado interés en el desempeńo económico de sus grandes ciudades y, por lo mismo, una escasez de estudios que analicen el proceso de redistribución de población y la reorientación de flujos migratorios al interior de la ciudad-región. Con datos censales, este estudio examina la reorientación de flujos migratorios al interior de la Región Centro de México, destacando el papel de la Zona Metropolitana de la Ciudad de México como el centro urbano dominante para el período 2000-2015. Se hace énfasis en los saldos migratorios netos entre zonas metropolitanas, ciudades medias, ciudades pequeñas y zonas rurales para identificar los espacios más atractores y expulsores. Además, se demuestra cómo la migración rural-urbana ha perdido importancia, mientras los flujos migratorios de mayores magnitudes son los metropolitanos-metropolitanos y los urbanos-metropolitanos.

PALABRAS CLAVE | desarrollo regional y local, migración, metropolización.

ABSTRACT | The city-region is identified as a new and dominant form of urbanization, which - in most cases - consists of a large city with other smaller surrounding urban centers. In the analysis of city-regions there has been a bias towards the economic performance of the larger city, resulting in a scarce number of studies regarding the population redistribution and the reorientation of migration flows for the city-region as a whole. Based on census data, this study analyzes the reorientation of migration flows at the interior of the Central Region of Mexico for the period 2000-2015, emphasizing the role of Mexico City as the dominant center. Particular attention is given to net migration balances between metropolitan areas, middle-sized cities, small cities, and rural areas. The analysis demonstrates that whereas rural-urban migration has lost relevance, metropolitan-to-metropolitan and urban-to-metropolitan migration flows are now the most important.

KEYWORDS | regional and local development, migration, metropolization. 


\section{Introducción}

A pesar de que las ciudades-región se han convertido en una forma de urbanización dominante en diversas regiones del mundo, existen pocos estudios que se enfoquen en la dinámica de los flujos migratorios al interior de esas ciudades-región, particularmente tomando como referencia principal a su ciudad más grande. Esta dinámica demográfica y migratoria al interior de la región es de fundamental importancia para identificar, tanto conceptual como empíricamente, la fase de concentracióndesconcentración en que se encuentra el subsistema urbano regional, y la transformación que han experimentado los centros urbanos con el impacto del nuevo modelo de apertura comercial.

El objetivo central de este trabajo es analizar el intercambio de población migrante entre la gran metrópoli de México y su sistema urbano más inmediato dentro de su región circundante, para saber en qué medida el grado de desconcentración urbana ha impactado no solo a ciudades medias, sino también a las de tamańo pequeńo, e incluso a las zonas rurales. Los resultados proporcionan información muy valiosa acerca de la fase de atracción y expulsión de población migrante de los centros urbanos de diferentes tamaños, así como de las zonas rurales, en relación sobre todo con su localización geográfica y su dinámica económica reciente. Planteado de otra manera, este análisis trata de aportar evidencias a las siguientes dos preguntas: ¿cómo han cambiado los patrones de flujos migratorios en la región, por tamaño de localidad y por destinos urbanos y rurales? y ¡cómo están distribuidos espacialmente a través de toda la región los diferentes tipos de migración, rural-urbana, urbanaurbana, metropolitana-metropolitana, etcétera?

El aporte principal de este trabajo en relación con otros sobre la Zona Metropolitana de la Ciudad de México (ZMCM) y sobre la migración interna en el país es que se analizan en detalle los flujos migratorios por tamańo de localidad al interior la Región Centro, que es la que contiene la ciudad más grande de México. Se los analiza por origen y por destino con los datos más actuales de que se dispone para dos períodos: 1995-2000 y 2010-2015. Es decir, se evalúa el fortalecimiento de los espacios más atractivos y el consiguiente debilitamiento de aquellos antes importantes, y se identifica la importancia que han adquirido los diferentes tipos de migración entre categorías metropolitanas, urbanas y rurales.

\section{La ciudad-región y la desconcentración urbana}

Uno de los fenómenos urbanos que más ha atraído la atención en las últimas dos décadas es el desarrollo de las llamadas ciudades-región; ellas se han multiplicado a nivel global y sus dimensiones han aumentado considerablemente, hasta convertirse en fenómenos regionales de varios millones de habitantes, con una marcada integración funcional en su interior. El argumento central del término ciudad-región es que no se puede separar la escala urbana-metropolitana de la regional; la transformación de la relación que existe entre la gran metrópoli y el espacio regional que la rodea ha sido uno de los cambios más importantes en la difusión del proceso urbano en el territorio. Por esta razón es que en los últimos diez años se ha despertado un 
renovado interés en este concepto, que se refleja en una variedad de trabajos a nivel internacional. ${ }^{1}$

La importancia que tiene la ciudad-región es que se ha convertido en un elemento organizador de la economía de un territorio bien identificado. Como señala Parr (2005, p. 557), la ciudad-región concentra una ciudad principal de varios millones de habitantes y un espacio circundante de carácter rural, pero que también puede incluir varias ciudades de diferentes tamaños. La ciudad principal representa una gran zona urbana continua, y contigua a otros territorios urbanos o rurales, de grandes dimensiones, en la mayor parte de los casos de carácter metropolitano. A lo largo de los ańos ha ido concentrando una actividad manufacturera importante, actualmente presenta un amplio rango de servicios especializados y es un importante nodo de comunicaciones y transportes. Por su parte, el territorio circundante, tanto rural como urbano, está muy vinculado con la ciudad principal. En él se producen alimentos y otras materias primas, pero también bienes manufacturados; presenta formación de clústeres especializados y es destino de actividades recreacionales y fuente de mano de obra.

Algunos de los cambios más significativos que ha experimentado la ciudadregión, desde el trabajo de Gottmann en 1961 sobre la megalópolis, afectan a varios de sus rasgos más importantes: (i) su carácter posindustrial se ha acentuado al experimentar la transición de la manufactura al dominio del sector servicios; (ii) no tiene límites precisos (edgeless) en términos regionales, aunque existen algunos avances en definir fronteras metropolitanas y regionales; (iii) se encuentra más desconcentrada y presenta una escala mucho mayor; (iv) nuevas zonas de crecimiento económico han surgido, lo cual estimula la migración interna y los flujos laborales. La redistribución de población en la ciudad-región está muy vinculada a las formas urbanas emergentes, como son la proliferación de extensas zonas periurbanas, la consolidación de nuevas zonas metropolitanas y el surgimiento de centros urbanos de pequeñas dimensiones (Vicino, Hanlon \& Short, 2007, pp. 361-364).

Con la multiplicación de este proceso, lo que identificamos es una nueva forma de urbanización dominante: regiones con una red policéntrica de muchas ciudades grandes, medias y pequeńas, separadas físicamente, pero vinculadas funcionalmente; aglomeradas alrededor de una o dos grandes metrópolis y que obtienen una gran fortaleza económica de una nueva división funcional del trabajo (Lang \& Knox, 2009, p. 791). De hecho, con el aumento de los estudios sobre la ciudad-región, la mayoría de los análisis se ha centrado en la dinámica de la metrópoli principal, en la posición de las ciudades en la economía global o en la competitividad económica de

1 Véase al respecto el número especial de Regional Studies, 43(6), julio de 2009: "The Futures of the City Region" [http:/www.tandfonline.com/toc/cres20/43/6?nav=tocList]. También Morril, 2006; Nelles, 2013; Parr, 2005; Purcell, 2007; Scott, 2001 y 2008; Vicino, Hanlon y Short, 2007. No puede dejar de mencionarse el trabajo de Jean Gottman (1961), Megalopolis: The Urbanized North-Eastern Seaboard of the United States, que fue un antecedente esencial de los estudios sobre ciudad-región. Uno de los temas principales en este trabajo era el de la desconcentración urbana de población y de actividades económicas en una franja de metrópolis interconectadas que se extendía de Boston a Washington D.C., con aproximadamente 37 millones de personas en ese momento. 
las principales actividades productivas, en el policentrismo o en los flujos laborales diarios; es decir, en gran medida ha existido un marcado interés en el papel económico de las grandes ciudades en este tipo de territorios. Por lo mismo, ha existido una escasez de estudios que analicen el proceso de redistribución de población, y con ello la reorientación de flujos migratorios al interior de la ciudad-región.

Evidentemente existe una fuerte interdependencia entre las dos grandes zonas, la ciudad principal y su espacio regional circundante, en términos de actividades complementarias y de oferta y demanda. Este rasgo característico se refleja en toda una serie de interacciones sociales y económicas, como son los flujos de comercio de diversos productos, servicios financieros y de negocios, flujos laborales diarios (commuting), o flujos de capital e inversión; y todo ello a través de la manifestación física de la interacción, que son las rutas de transporte de carácter radial entre estos dos grandes espacios. Pero existe otro tipo de flujos que se pueden denominar "flujos redistributivos", los cuales tienen un efecto a más largo plazo y afectan la estructura espacial de la ciudad-región (Parr, 2005, p. 560). Los dos ejemplos más típicos son los movimientos migratorios de la población y los cambios locacionales del capital asociados a la actividad económica.

La integración de actividades económicas y sociales a una escala regional genera un alto grado de movilidad de la población dentro de las fronteras de ese territorio. En la medida en que los mercados de trabajo y de vivienda se vuelven más accesibles a escala regional, las distancias de viaje se amplían, y ello no solo con fines de trabajo, sino también para fines recreativos, de compras, etcétera (Wheeler, 2009, p. 864). Esta nueva dinámica demanda mayor infraestructura de transporte, a la vez que se incrementan los viajes en vehículos privados debido a la dispersión de actividades, sobre todo en los centros urbanos, los cuales constituyen nuevos destinos. Es común que un alto número de trabajadores se desplace diariamente entre ciudades varias decenas de kilómetros, pero también que una gran proporción de población cambie de lugar de residencia.

Uno de los temas cruciales en la ciudad-región es la evolución que ha tenido la ciudad principal en términos de su papel concentrador de población y como nodo de atracción o expulsión de población migrante. Según las teorías urbanas sobre el ciclo del desarrollo urbano, como aquella de la urbanización diferencial (Geyer \& Kontuly, 1996), este ciclo pasa por varias etapas, en las que la gran ciudad experimenta distintos ritmos de crecimiento poblacional a través del tiempo. En la fase inicial, llamada de concentración y primacía, se registra el mayor crecimiento poblacional; en la segunda fase, de reversión de la polaridad, disminuye su ritmo de crecimiento y son las ciudades intermedias cercanas las que crecen más rápidamente, constituyendo los polos de la desconcentración urbana; en la tercera fase sucede un proceso de contraurbanización, donde son las ciudades pequeñas, e incluso las zonas rurales, las que presentan más dinamismo poblacional; para finalmente llegar a una cuarta fase, donde las ciudades principales retoman su papel de polos de mayor crecimiento.

En este proceso, los flujos migratorios explican en gran medida las variaciones de las diferentes fases. En la fase de concentración y primacía, los flujos de naturaleza rural-urbana son los predominantes; en la etapa de reversión, los flujos migratorios 
se diversifican y tienen como destino principal las ciudades medias cercanas; posteriormente, en la contraurbanización, los flujos son predominantemente urbanosurbanos y se dirigen a los centros urbanos de jerarquías menores. Hay que señalar que el modelo distingue entre flujos primarios, o sea, los de mayor magnitud, y flujos secundarios, que serían los de menor magnitud; es decir, aunque la ciudad principal deje de recibir flujos primarios, no deja de recibir flujos secundarios. La población tiende a migrar a zonas donde sus perspectivas de un mejor nivel de vida son mejores; para los grupos más pobres, mejores condiciones de vida significan generalmente un mejor empleo; para los grupos de mayor nivel socioeconómico, mejores condiciones pueden significar desplazarse a un lugar más seguro y de mayor calidad ambiental (Geyer, 2002, p. 31).

En América Latina, el crecimiento de las grandes ciudades ha mostrado importantes transformaciones. Primero, y en consonancia con el modelo económico sustitutivo de importaciones, la dinámica productiva produjo una concentración industrial y una fuerte atracción migratoria hacia la ciudad principal. Luego, la adopción de un modelo económico neoliberal durante los ańos ochenta y la mejora en la infraestructura carretera propiciaron la desconcentración de procesos productivos hacia otras ciudades. Gradualmente se fueron presentando las siguientes etapas del ciclo urbano, donde las deseconomías de aglomeración, debidas a la concentración poblacional, la contaminación y el encarecimiento del nivel de vida en la ciudad principal, desencadenaron la desconcentración urbana hacia centros cercanos y después a los más alejados. En la última fase, varias de las ciudades principales en la región, después de ser centros claramente atractores, se han convertido en núcleos expulsores de población (Chávez Galindo et al., 2016, pp. 11-12). En la mayoría de los casos, las ciudades grandes siguen incrementando su peso en la población total y continúan siendo de atracción migratoria, pero las de más de 10 millones de habitantes, megalópolis, tienden a ser de emigración neta (Rodríguez Vignoli, 2016, p. 23). Es decir, es prioritario saber, en ciudades-región específicas, el papel que desempeñan actualmente las grandes ciudades como nodos concentradores y atractores de flujos migratorios, y el tipo de intercambios migratorios que mantienen con el resto de centros urbanos de su propia región. Ello sobre todo por el enorme peso poblacional que representan estas ciudades-región en el sistema urbano de cada país.

\section{La Región Centro de México}

A la Región Centro de México generalmente se la ha considerado la ciudad-región de la Ciudad de México. La Región Centro (RC) está integrada por siete estados: Ciudad de México (antes Distrito Federal), ${ }^{2}$ y estados de México, Hidalgo, Morelos, Puebla, Querétaro y Tlaxcala.

La RC cubre un área de 97.964 kilómetros cuadrados, que representa el 5\% del territorio nacional; sin embargo, su concentración poblacional es sumamente alta:

En el decreto del 29 de enero de 2016 y de acuerdo con la reforma política llevada a cabo, se establece que el término Ciudad de México será la denominación que de ahí en adelante se dará a la entidad federativa que la contenía, que era el Distrito Federal. 
en 2015 contenía a 39,3 millones de habitantes, que representaban el 33,1\% de la población total del país. Se trata de un territorio muy urbanizado, donde las zonas metropolitanas y los centros urbanos han concentrado a la gran mayoría de la población; al respecto, la población urbana total representa el $84 \%$ del total regional. La RC mantiene un papel destacado a nivel nacional, ya que concentra el $46 \%$ de la población metropolitana del país; produce el 35\% del producto interno bruto; y contiene la más alta proporción de las unidades productivas y de la población empleada, con el $35,4 \%$ y el $36,1 \%$, respectivamente.

La dinámica del crecimiento urbano en la RC ha pasado por tres principales fases en los últimos cincuenta ańos: en primer lugar, un fuerte proceso de concentración urbana en la Ciudad de México hasta los años setenta; en segundo término, el inicio de un proceso de reversión de la polaridad en los ańos setenta, donde las ciudades más grandes y cercanas a la ciudad capital empezaron a recibir los efectos descentralizadores y a incrementar su dinámica urbana; finalmente, una tercera etapa, a finales del siglo pasado y en la primera década de este siglo, de intensa expansión metropolitana y crecimiento urbano en otras zonas metropolitanas, y en las jerarquías menores de ciudades medias y pequeñas (Aguilar, 2003, pp. 44-48; y 2016).

Los análisis recientes de la RC ponen énfasis en varios procesos importantes: (i) primero, a partir de la adopción de un modelo económico neoliberal se reestructuró la actividad económica y se desconcentró la población bajo un modelo de "desconcentración concentrada", que estimuló el crecimiento de los centros urbanos mayores, varios de los cuales se convirtieron en grandes zonas metropolitanas; (ii) segundo, la actividad primaria perdió importancia y el sector manufacturero se dispersó a los centros urbanos; en la ciudad primaria fue muy claro el proceso de "desindustrialización", y el sector servicios se volvió predominante, con altas especializaciones en las metrópolis principales; (iii) la desconcentración de población incrementó visiblemente el carácter urbano de la RC, multiplicando el tamaño y número de los centros urbanos; la ciudad central perdió poder de atracción y los flujos migratorios se reorientaron hacia las ciudades económicamente más dinámicas; y (iv) la migración interna hoy presenta un patrón más complejo en todo el país; después de una fase de migración rural-urbana predominante, actualmente se pueden apreciar movimientos migratorios metropolitanos-metropolitanos, urbanos-urbanos, urbanos-rurales y rurales-urbanos, lo cual en gran medida se refleja en esta región (véase Aguilar, 2003, pp. 44-58; Chávez \& Guadarrama, 2004, pp. 180-183; Olivera \& Galindo, 2013, pp. 422-423; Pérez Campuzano, 2006, pp. 363-364). Estudios más recientes sobre el aspecto migratorio señalan cómo la migración interna en el país ha disminuido su intensidad desde 1980, y que la migración urbana-urbana parece ser el flujo predominante en la movilidad interna (Sobrino, 2010, pp. 103-107; y 2016, pp. 73-74).

Aunque a nivel nacional los flujos migratorios hacia la RC han disminuido en magnitud, continúan siendo importantes los que se dirigen hacia las principales entidades que contiene la ZMCM, como son la actual Ciudad de México (antes Distrito Federal) y el Estado de México. Estas entidades han recibido el monto mayor de migrantes de la RC en las últimas décadas, incluso durante la adopción del modelo de apertura comercial, y continúan siendo relevantes (Sobrino, 2010, pp. 
69-70). Pero a la vez que estas entidades reciben alto número de migrantes, también muestran un intenso intercambio poblacional al expulsar un flujo importante de población. La tabla 1 muestra cómo la RC registra un saldo neto migratorio positivo con el resto de entidades del país, pero con altos intercambios de entradas y de salidas, y que la Ciudad de México y el Estado de México reciben y expulsan a la mayoría de dicha población migrante.

TABLA I | Región Centro: saldo neto migratorio con respecto al resto de estados del país, 2015

\begin{tabular}{|l|r|r|r|}
\hline \multicolumn{1}{|c|}{ REgión CENTRO } & ENTRADAS & SALIDAS & SALDO NETO \\
\hline Ciudad de México & 98.752 & 129.894 & -31.142 \\
\hline Hidalgo & 26.838 & 25.952 & 886 \\
\hline México & 116.724 & 111.571 & 5.153 \\
\hline Morelos & 35.716 & 21.380 & 14.336 \\
\hline Puebla & 61.249 & 55.785 & 5.464 \\
\hline Querétaro & 59.124 & 22.442 & 36.682 \\
\hline Tlaxcala & 8.693 & 7.159 & 1.534 \\
\hline & $\mathbf{4 0 7 . 0 9 6}$ & 374.183 & 32.913 \\
\hline
\end{tabular}

FUENTE CÁlCULOS PROPIOS CON DATOS DE LA ENCUESTA INTERCENSAL 2O I 5 , INSTITUTO NACIONAL DE ESTADÍSTICA Y GEOGRAFÍA (INEGI)

Es así que el proceso de desconcentración urbana ha sido el rasgo predominante en la RC en los últimos treinta ańos. La tabla 2 muestra la gradual disminución de la participación de la ZMCM en el crecimiento urbano de la región y su pérdida de atracción. Paralelamente se advierte el proceso de concentración urbana en otras metrópolis regionales, con un movimiento de redistribución urbana desde el "centro" a la "periferia” y hacia los niveles más bajos de la jerarquía urbana. En 1970, la población de la ZMCM representaba la mitad de la población urbana de la RC, y como resultado de la desaceleración del crecimiento de la ZMCM, su tasa de crecimiento fue de 1,7\% en el período 1990-2000 y de 0,8\% en el lapso 2010-2015.

Mientras que en 1970 existían solo dos zonas metropolitanas en la RC (la ZMCM y la zM de Puebla), para 2010 ya existían 13 zonas metropolitanas. En 2010, el total de población de las zM era de 30,8 millones de habitantes, lo cual significa un incremento de 15 millones respecto a la población en zM en 1980. Estos datos seńalan el fuerte proceso de metropolización que está teniendo lugar en la región. Mientras que la ZMCM registró la tasa de crecimiento más baja, las zM de Pachuca y Querétaro registran las tasas de crecimiento más altas, con 3,0\% en la última década. 


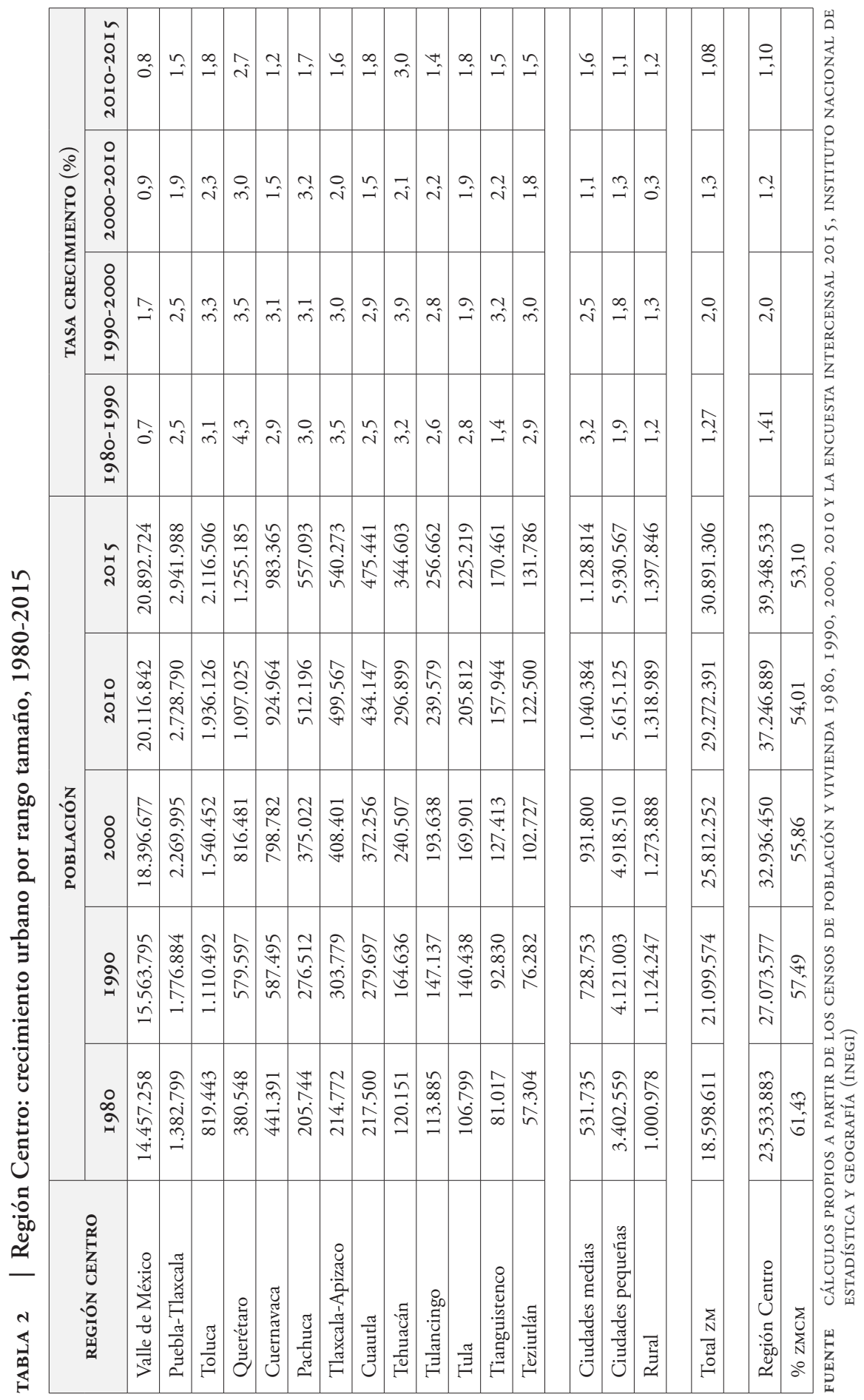


FIGURA I | Región Centro: distribución de las zonas metropolitanas y ciudades medias y pequeńas, 2010

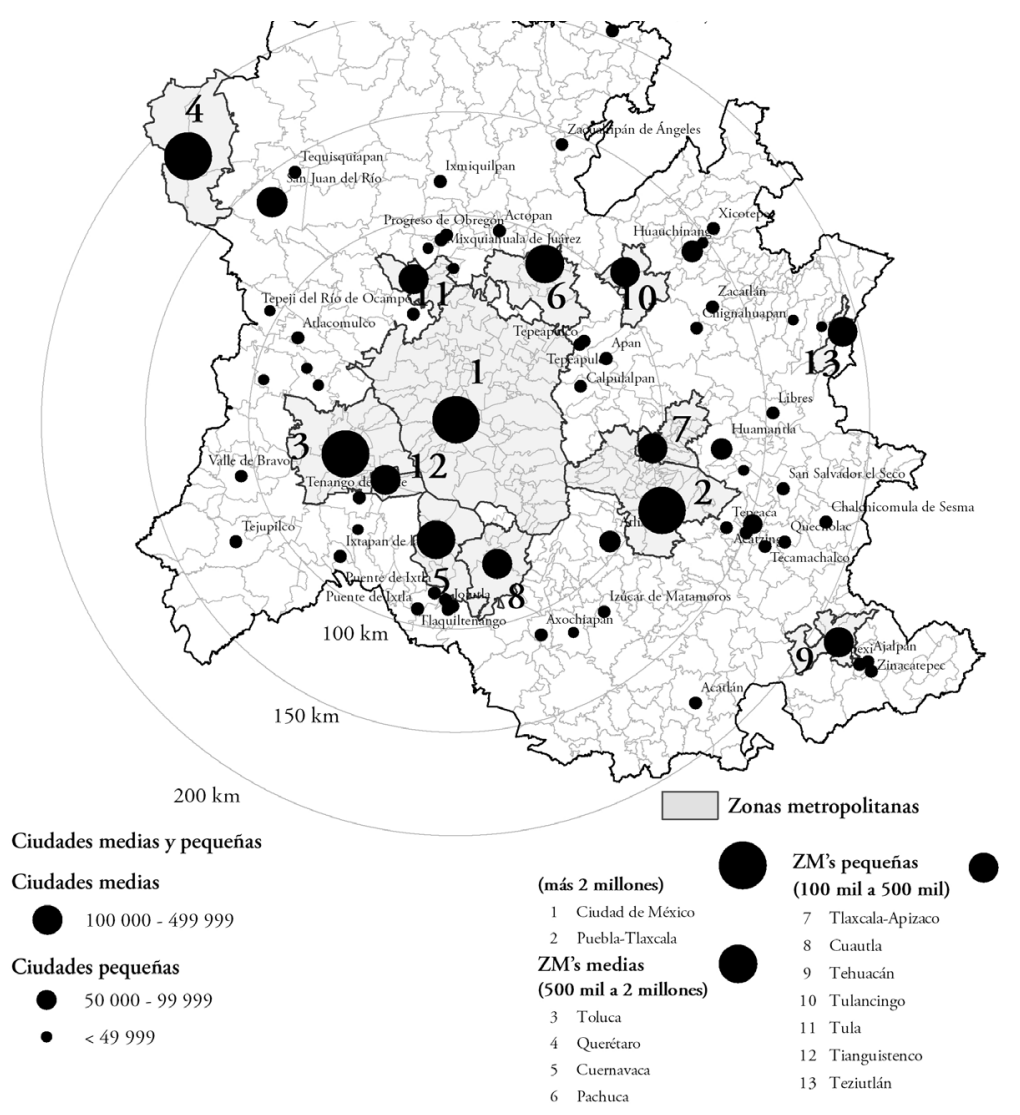

FUENTE ELABORACIÓN PROPIA A PARTIR DEL CENSO DE POBLACIÓN Y VIVIENDA 2OIO, INSTITUTO NACIONAL DE ESTADÍSTICA Y GEOGRAFÍA (INEGI)

De acuerdo con estos datos, las ciudades más grandes han registrado las tasas más bajas de crecimiento (alrededor de 1\%); las ciudades intermedias crecen un poco más rápido, con tasas por arriba del 1\% (1,32\%); y las ciudades de menor tamaño registran el crecimiento más acelerado, con tasas promedio de 3\%. Este proceso ha dado lugar a una redistribución de población a favor de ciudades medias y pequeñas, sobre todo aquellas cercanas a zonas metropolitanas, formando así una gran dispersión urbana y una periurbanización de zonas muy alejadas de las ciudades centrales (tabla 2 y figura 1 ).

En términos teóricos, se considera que según el ritmo de crecimiento y el proceso de desconcentración de la gran metrópoli (la Ciudad de México), y siguiendo el modelo de urbanización diferencial de Geyer y Kontuly (1996), la RC se encontraba a principios del presente siglo en la fase de las ciudades intermedias, que indica que el crecimiento urbano más acelerado estaba sucediendo en las ciudades medias no 
solo cercanas, sino también en las más alejadas de la ciudad principal, y esta última había disminuido su crecimiento, pero aún recibía un flujo migratorio de magnitud secundaria (Aguilar \& Graizbord, 2002, pp. 432-433).

\section{Los flujos migratorios por tamańo de localidad en la ciudad-región}

En esta sección intentamos responder las dos preguntas señaladas al comienzo de este trabajo: ¿cómo han cambiado los patrones de flujos migratorios en la región, por tamaño de localidad y por destinos urbanos y rurales?, y ¿cómo están distribuidos espacialmente los diferentes tipos de migración a través de toda la región? Este análisis se realiza para los flujos migratorios por tamaño de localidad en la RC en los períodos 1995-2000 y 2010-2015, para lo cual se utilizaron los tabulados de la muestra censal de los censos de población de 2000 y 2015. ${ }^{3}$ También se utilizan los censos económicos de los años 1999 y 2014, que presentan una casi total coincidencia con los censos de población de los mismos ańos, por lo que se puede afirmar que las relaciones entre comportamientos sociodemográficos y económicos son altamente válidas.

El aporte principal de este trabajo en relación con otros ya referidos es que se analizan en detalle los flujos migratorios por tamaño de localidad al interior la RC, según origen y destino, con los datos más actuales de que se dispone; es decir, se evalúa la atractividad de cada categoría urbana, e incluso de las zonas rurales. Específicamente, el análisis se centra mayoritariamente en la migración interna en la ciudad-región, particularmente con la siguiente estructura:

- Los saldos migratorios a nivel de toda la Región Centro por tamaño de localidad, con énfasis en la magnitud de los flujos migratorios de entrada y salida.

- El caso de la Zona Metropolitana de la Ciudad de México, por su importancia como ciudad principal, con atención a la evolución reciente de la intensidad migratoria según flujos de entrada y de salida.

- Los intercambios de flujos migratorios entre el resto de localidades urbanas y zonas rurales, para destacar la movilidad principal entre las categorías metropolitanas, urbanas y rurales.

Para el desarrollo del análisis se realizan, como tareas importantes, la estimación del volumen migratorio al interior de la región y el análisis de los flujos según lugares de origen y destino.

Respecto al tamaño de los centros urbanos y de las zonas metropolitanas, para este análisis se clasificaron de la siguiente manera: las ZM grandes están representadas por las dos ciudades mayores de la región, la Ciudad de México y PueblaTlaxcala, prácticamente superiores a 3 millones de habitantes; las ZM medianas son las del rango de 500.000 a menos de 2 millones de habitantes; y las ZM chicas, aquellas cuya población es inferior a 500.000 habitantes. Por otro lado, las ciudades

3 Es importante aclarar que en el año 2000 se elaboró un censo de población, pero en el 2015 solo se aplicó una encuesta intercensal. 
medianas son las que se encuentran en el rango de 100.000 a menos de un millón de habitantes, que no son zonas metropolitanas; y las ciudades chicas son aquellas de 15.000 a menos de 100.000 habitantes, que tampoco son zonas metropolitanas. ${ }^{4}$

\section{Los saldos migratorios en la Región Centro por tamaño de ciudad}

En esta sección se presentan los resultados del balance migratorio tanto de las ZM como de las ciudades medias y pequeñas en dos períodos: a principios de siglo, 1995-2000, y quince años después, para el período 2010-2015. Según los resultados, se clasifican las ciudades en las categorías de expulsoras o atractoras. Para algunos centros urbanos se mantiene la categoría entre los períodos estudiados, pero para algunas ciudades estas categorías sufren un cambio significativo, que es muy indicativo de su dinámica económica (tabla 3).

De los centros urbanos con la categoría de expulsores, en primer lugar hay que destacar las ZM más grandes de la región, la Ciudad de México y Puebla-Tlaxcala, las cuales en gran medida se mantienen como centros que expulsan más población de la que reciben. Cabe señalar que Puebla-Tlaxcala cambió su condición de atractora a expulsora entre el primero y el segundo período. Este es un aspecto sobresaliente porque muestra un proceso de desconcentración de población y de pérdida de oportunidades económicas en las ciudades más grandes, muy de acuerdo con el modelo de urbanización diferencial ya señalado. Sin embargo, hay que resaltar que ambas ciudades siguen incrementando su peso poblacional y recibiendo flujos migratorios secundarios o de baja dimensión.

En segundo lugar, también como expulsoras sobresalen en el otro extremo algunas de las zM chicas, como Tlaxcala-Apizaco, Tehuacán, Teziutlán y Tianguistenco. La primera de ellas cambió su categoría de atractora a expulsora en el período, y la última muestra una fuerte expulsión, considerando la magnitud de los flujos de salida. Cabe mencionar que dos de las mencionadas están en el estado de Puebla, lo cual es una situación preocupante para este estado, porque todas sus ZM son prácticamente expulsoras de población. Estos centros urbanos pequeños están relacionados con un decaimiento de actividad industrial y de industria maquiladora, como Tianguistenco y Tehuacán, respectivamente, y de actividades agropecuarias en Teziutlán.

Estos rangos en los tamańos de ciudades ya han sido usados en otros análisis del sistema urbano nacional; véase Aguilar, 2014, pp. 197-199; y Secretaría de Desarrollo Social (Sedesol), Consejo Nacional de Población (Conapo) e Instituto Nacional de Estadística y Geografía (Inegi), 2010. 


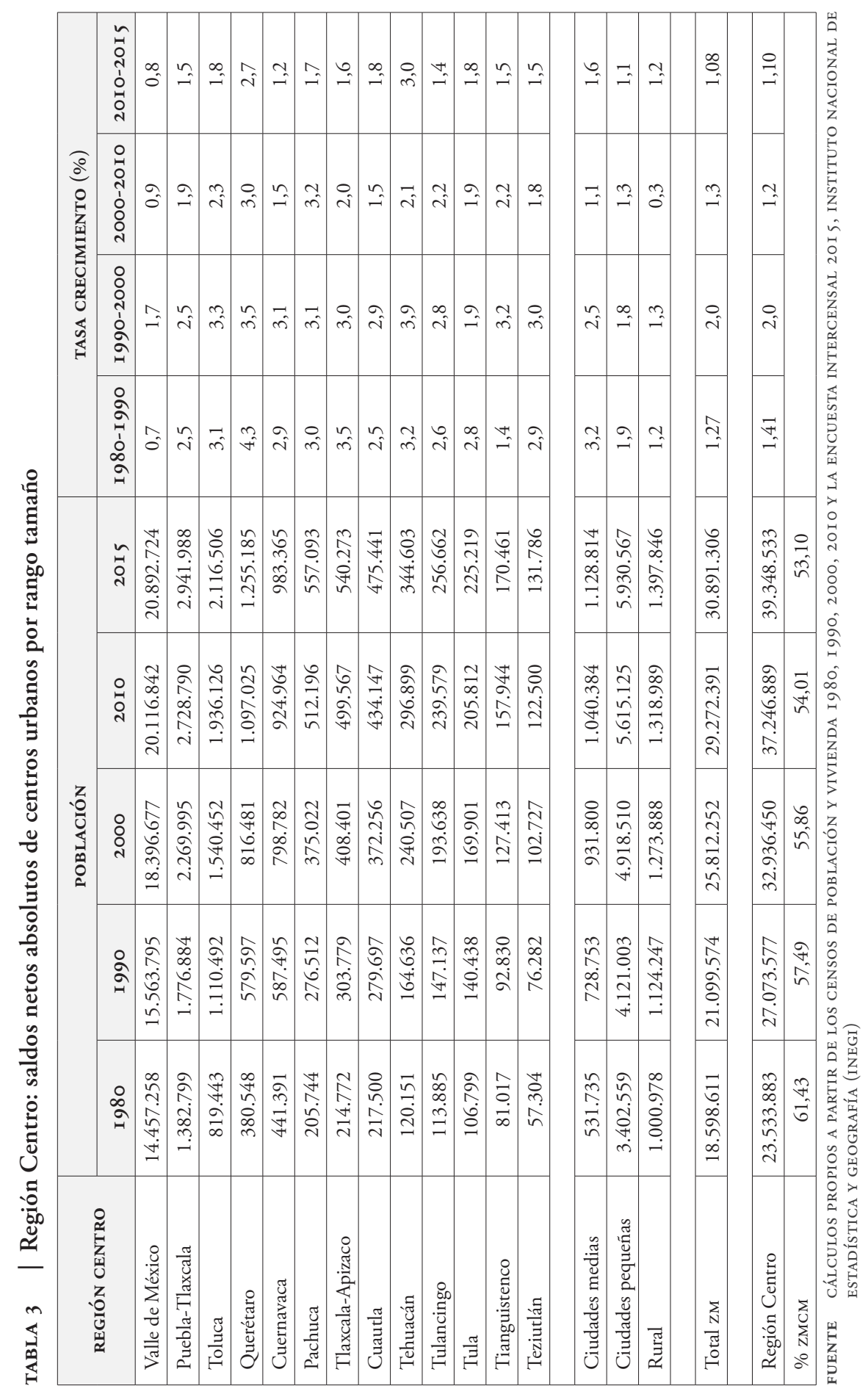


Considerando el comportamiento de los sectores productivos por ZM en el período 1999-2014, encontramos mucha congruencia con el comportamiento de los flujos migratorios. El sector manufacturero tuvo pérdida de empleos en cuatro de las ZM mencionadas como expulsoras de población (Valle de México, Tehuacán, Teziutlán y Tianguistenco); y en estas mismas zM se nota en el mismo período una caída del valor agregado censal bruto en alguno de sus sectores económicos (véase tabla 4), sobre todo el manufacturero. Dos casos típicos de ciudades ganadoras y perdedoras en este período son Cuernavaca y Querétaro: la primera fue una de las ciudades beneficiada por el modelo sustitutivo de importaciones y la segunda se vio beneficiada por el modelo de apertura comercial. En 1990 tenían casi el mismo número de habitantes y gradualmente Querétaro fue superando a Cuernavaca en población y en dinámica económica. La metrópoli queretana tiene una localización más ventajosa en su conexión al norte con el mercado estadounidense, un sector industrial en plena expansión y muy vigoroso, y un sector terciario con un crecimiento aún mayor, dando muestras de una economía posindustrial. Cuernavaca, en cambio, tiene una localización poco ventajosa, con conexión al sur del país, y muestra una economía poco próspera con actividades productivas en declive, particularmente la manufacturera, que habían sido su motor de desarrollo (Rodríguez, 2015, pp. 440-442).

TABLA 4 Región Centro: diferencias de población ocupada y de valor agregado censal bruto por zonas metropolitanas, 1999-2014

\begin{tabular}{|c|c|c|c|c|c|c|}
\hline \multirow{2}{*}{$\begin{array}{l}\text { REGIÓN } \\
\text { CENTRO }\end{array}$} & \multicolumn{3}{|c|}{ PERSONAL OCUPADO } & \multicolumn{3}{|c|}{$\begin{array}{l}\text { VALOR AGREGADO CENSAL BRUTO }\left(^{*}\right) \\
\text { (MILES DE PESOS) }\end{array}$} \\
\hline & MANUFACTURA & COMERCIO & SERVICIOS & MANUFACTURA & COMERCIO & SERVICIOS \\
\hline Valle de México & -137.098 & 439.088 & 1.372 .479 & -65.998 .036 & -47.760 .198 & 261.097 .558 \\
\hline Puebla-Tlaxcala & 16.762 & 75.611 & 101.668 & 25.281 .743 & 5.168 .065 & 6.228 .092 \\
\hline Toluca & 45.767 & 60.981 & 70.741 & 12.649 .545 & 4.064 .668 & 5.149 .457 \\
\hline Querétaro & 70.559 & 45.927 & 81.516 & 3.887 .163 & 6.494 .040 & 10.167 .149 \\
\hline Cuernavaca & 5.525 & 22.252 & 36.950 & -2.402 .161 & 2.126 .275 & 1.604 .071 \\
\hline Pachuca & -282 & 19.483 & 30.554 & -54.634 & 2.269 .575 & 1.630 .584 \\
\hline Tlaxcala-Apizaco & 141 & 15.125 & 16.556 & 303.888 & 956.120 & 776.664 \\
\hline Cuautla & 6.155 & 11.107 & 14.721 & 2.121 .475 & 986.597 & 1.515 .555 \\
\hline Tehuacán & -10.408 & 12.456 & 9.391 & -893.057 & -1.705 .161 & 606.470 \\
\hline Tulancingo & -1.346 & 6.260 & 6.030 & -547.302 & 460.346 & 250.425 \\
\hline Tula & 8.423 & 7.068 & 6.254 & 6.259 .774 & 962.100 & 297.273 \\
\hline Tianguistenco & -2.914 & 4.331 & 2.142 & 1.306 .138 & 496.634 & -1.481 .010 \\
\hline Teziutlán & -2.394 & 3.384 & 1.770 & -674.601 & 153.998 & -124.648 \\
\hline Resto RC & 56.070 & 144.269 & 102.773 & -4.161 .913 & 7.449 .653 & 4.288 .999 \\
\hline Región Centro & 54.960 & 867.342 & 1.853 .545 & -22.921 .978 & -17.877 .289 & 292.006 .640 \\
\hline
\end{tabular}

(*) EL VALOR AGREGAdo CENSAL BRUTO FUE DEFLACTADO CON EL DEFLACTOR IMPLÍ́CITO DEL PIB (BASE $2006=$ IOO).

FUENTE CÁlCUlos PROPIOS CON DATOS DEL CENSO ECONÓMICO I 999 Y 20 I 4, INSTITUTO NACIONAL DE ESTADÍSTICA Y GEOGRAFÍA (INEGI) 
En la misma categoría de expulsoras se puede agrupar a las ciudades pequeñas y las zonas rurales. En los dos períodos, ambas categorías han mostrado sistemáticamente mayor salida de población migrante de la que se siente atraída por estas zonas. Quizá no es de extrañar que las zonas rurales se mantengan como expulsoras de población ante el poco apoyo al campo que ha existido en las últimas décadas, las condiciones de pobreza que predominan en ellas y la fuerte tendencia a la urbanización en la región; pero el caso de las ciudades más chicas sí es sorprendente porque, por su alto incremento en número, era de esperar que fueran centros económicamente dinámicos y con infraestructuras de mejor calidad. No obstante, las condiciones de vida que presentan no son lo suficientemente satisfactorias para retener población, ni tampoco para atraer migrantes, situación ya señalada por Rodríguez Vignoli (2016, p. 23) para este tipo de ciudades en algunos países de América Latina.

Ahora bien, considerando los centros urbanos atractores, es de destacar que las ZM de tamaño medio (de 550.000 a prácticamente 2 millones) son las que presentan saldos migratorios positivos; ejemplos son Toluca, Querétaro, Cuernavaca y Pachuca; en el caso de las zM chicas sobresalen Tula y Cuautla. Con ello se nota una diversificación de destinos para los migrantes en nodos alrededor de la zM de la Ciudad de México tanto en ciudades millonarias como de tamaño intermedio, y con ello se confirma la desconcentración de oportunidades económicas a estos centros. Si examinamos los indicadores económicos de creación de empleo y de valor agregado censal bruto, observamos cómo efectivamente las zM mencionadas presentan incrementos importantes en ambas variables; sobresalen al respecto Toluca y Querétaro como las ZM con la más alta generación de empleos, tanto en actividades terciarias como en manufactureras (tabla 4).

Asimismo, es interesante señalar que también las ciudades medias no metropolitanas se han mostrado como polos atractores importantes para los flujos migratorios de llegada.

\section{La Zona Metropolitana de la Ciudad de México}

La ZMCM es la gran metrópoli de la región y quizá por lo mismo ha experimentado una fuerte transformación en términos de flujos migratorios de entrada y salida; después de ser un nodo fuertemente atractor de migrantes, se convirtió en un núcleo expulsor en los últimos veinte años. El ritmo de crecimiento de zмсM es muy representativo de las tres fases ya descritas para la RC. Hasta los años setenta, la ZMCM había crecido a tasas muy altas y había sido la ciudad de mayor atracción poblacional en el país debido al proceso sustitutivo de importaciones, que concentró en ella una alta proporción de actividad industrial; los movimientos migratorios rurales-urbanos alimentaron su crecimiento por varias décadas, alcanzando tasas por arriba del 5\%; ello hasta que en la década de los ańos setenta su ritmo de crecimiento empezó a disminuir y las ciudades cercanas vieron aumentar su dinámica urbana como resultado de procesos desconcentradores de población y de actividad económica.

En 1982, la crisis económica afectó al país y desencadenó varios procesos que convirtieron a la ciudad capital en poco atractiva; disminuyó la inmigración y se estimularon procesos centrífugos de urbanización; algunos sectores económicos 
-como, por ejemplo, el de la construcción- tuvieron tasas negativas entre 1982 y 1986; la tasa de desempleo urbano creció notablemente; se registró una tasa de inflación muy elevada que encareció la vida urbana; y en general la inversión pública disminuyó en todos los sectores. A lo anterior hay que agregar los efectos del terremoto de 1985, que provocaron movimientos desconcentradores de población de clase media y obligaron al sector público a tomar medidas de descentralización administrativa (Aguilar, 2003, p. 38).

En los últimos quince años, la dinámica económica de la zMCM ha dado muestras de un claro proceso de desindustrialización junto a una marcada terciarización de su economía. Gradualmente esta gran ciudad ha perdido empleos en el sector manufacturero, que se han desconcentrado no solo hacia otros centros urbanos de la Región Centro, sino también a otras ciudades de las regiones centro-norte y norte del país; así, en el período 1999-2014 se perdieron 137.098 empleos en este sector. Este hecho ha sido un factor importante para disminuir el poder de atracción de población de la ZMCM, dado que el crecimiento de su sector comercio y servicios -como diversos estudios lo han reportado- ha generado empleos de baja calificación y muy bajo ingreso, muchos de ellos en la informalidad. Aun así, en el mismo período se generaron poco más de 1,8 millones de empleos en el sector comercio y servicios de forma global, lo cual es un gran contraste con la situación del sector industrial (tabla 4).

Hay que recordar que la ZMCM se asienta en tres entidades principales, mayoritariamente en la Ciudad de México y el estado de México, y en menor medida en el estado de Hidalgo. A partir de 1970, el flujo migratorio hacia la ciudad central disminuyó sensiblemente; particularmente la Ciudad de México, después de ser una entidad de alta atracción, pasó a ser una entidad de expulsión de migrantes. Así, si en el período 1965-1970 entre el 40\% y 50\% de los emigrantes de las entidades de la RC tenían a la Ciudad de México como su principal destino, en la primera década de este siglo la proporción de migrantes de esos mismos estados a la Ciudad de México cayó notablemente a cifras entre 10\% y 30\%, según el estado de que se trate. Además, la Ciudad de México empezó a perder más población de la que recibía, y su población emigrante constituyó los mayores flujos hacia el resto de las entidades de la RC, alcanzando en algunos de ellos hasta el 30\% de sus inmigrantes (tabla 5).

Los datos de saldos netos migratorios de los últimos veinte años entre centros urbanos muestran que, en términos generales, la zMCM ha sido francamente expulsora de población migrante, ya que mantenía saldos negativos con la mayoría de zonas metropolitanas y centros urbanos menores. Al analizar por rango tamaño los saldos migratorios de la ZMCM a principios de siglo (1995-2000) y comparándolos con los de las demás ciudades, se observa que: (i) con la mayoría de ZM de mayor tamańo (mayores a 500.000 habitantes) mantiene un saldo negativo; (ii) los principales destinos de la población migrante de la ZMCM son ZM de alta dinámica económica con un predominio de actividad industrial, o centros de servicios o capitales de mucha cercanía, como Toluca, Querétaro, Cuernavaca y Pachuca. $\mathrm{Al}$ respecto, la gran excepción es la ZM de Puebla-Tlaxcala, la segunda ciudad en importancia en la región y con la cual se mantiene un saldo positivo, pues aún la 
gran metrópoli sigue siendo muy atractiva para los migrantes de esa ZM, de la cual recibe una alta cantidad de migrantes. (iii) En el caso de las ZM más chicas no existe un patrón regular: con algunas hay saldos negativos y con otras son positivos. Es interesante observar que en este mismo período se da una importante llegada a la ZMCM de migrantes de ciudades medias no metropolitanas y de ciudades pequeñas, en las cuales se nota aún la fuerte atracción que ejerce la Ciudad de México sobre la población de las jerarquías urbanas menores.

TABla 5 $\mid$ ZM del Valle de México: Migración de entrada y salida con saldos netos de otros centros urbanos

\begin{tabular}{|c|c|c|c|c|c|c|}
\hline \multirow{2}{*}{$\begin{array}{c}\text { ZM DE LA } \\
\text { CIUDAD DE } \\
\text { MÉXICO }\end{array}$} & \multicolumn{3}{|c|}{$1995-2000$} & \multicolumn{3}{|c|}{$2010-2015$} \\
\hline & ENTRADAS & SALIDAS & $\begin{array}{c}\text { SALDO } \\
\text { NETO } \\
\end{array}$ & ENTRADAS & SALIDAS & $\begin{array}{c}\text { SALDO } \\
\text { NETO } \\
\end{array}$ \\
\hline Pachuca & 5.545 & 14.443 & -8.898 & 7.172 & 15.877 & -8.705 \\
\hline Tulancingo & 2.312 & 3.933 & -1.621 & 1.098 & 1.866 & -768 \\
\hline Tula & 2.474 & 5.916 & -3.442 & 1.057 & 5.641 & -4.584 \\
\hline Toluca & 21.854 & 24.133 & -2.279 & 18.814 & 25.176 & -6.362 \\
\hline Cuernavaca & 7.449 & 16.942 & -9.493 & 8.681 & 9.912 & -1.231 \\
\hline Cuautla & 3.665 & 12.732 & -9.067 & 2.547 & 6.928 & -4.381 \\
\hline Puebla-Tlaxcala & 22.034 & 17.606 & 4.428 & 28.426 & 9.518 & 18.908 \\
\hline Tehuacán & 2.113 & 1.943 & 170 & 1.454 & 1.121 & 333 \\
\hline Querétaro & 5.336 & 24.617 & -19.281 & 7.049 & 18.469 & -11.420 \\
\hline Tlaxcala-Apizaco & 5.412 & 8.326 & -2.914 & 5.165 & 2.943 & 2.222 \\
\hline Tianguistenco & 16.385 & 1.878 & 14.507 & 19.846 & 1.262 & 18.584 \\
\hline Teziutlán & 604 & 514 & 90 & 266 & 195 & 71 \\
\hline Ciudades medias & 10.370 & 7.561 & 2.809 & 5.004 & 7.084 & -2.080 \\
\hline Ciudades pequeñas & 60.922 & 50.226 & 10.696 & 24.841 & 27.167 & -2.326 \\
\hline Rural & 19.810 & 18.847 & 963 & 6.622 & 6.711 & -89 \\
\hline & 186.285 & 209.617 & -23.332 & 138.042 & 123.993 & -1.828 \\
\hline
\end{tabular}

FUENTE CÁlCULOS PROPIOS CON DATOS DEL CENSO DE POBLACIÓN (200O) Y ENCUESTA INTERCENSAL 20 I 5 , INSTITUTO NACIONAL DE ESTADÍSTICA Y GEOGRAFÍA (INEGI)

En el último período, 2010-2015, prácticamente se mantiene la tendencia general anterior de saldos negativos con las zM de diferentes tamaños; es de notar que las zM de Puebla-Tlaxcala y la de Tianguistenco son las que envían las mayores cantidades de migrantes a la gran metrópoli. El cambio más significativo sucedió con las ciudades medias, las ciudades pequeńas y las zonas rurales: mientras que en el primer período se registraron saldos netos positivos con estas tres categorías, para el segundo dichos saldos se vuelven negativos; es decir, más migrantes salen de la ZMCM hacia estos centros más pequeños y zonas rurales en comparación con los que llegan, lo que lleva a suponer que por alguna razón los núcleos menores se volvieron más atractivos. Cabe señalar que los flujos de llegada más importantes provienen de las ciudades chicas. 
Por último, hay que resaltar que, para toda la ZMCM, después de tener un saldo migratorio negativo global en 1995-2000 de -23.332 migrantes, en el siguiente período, 2010-2015, ese mismo saldo es también negativo, con -1.828 migrantes, aunque -como se advierte- es de menores dimensiones. Estas cifras muestran cómo se mantienen tanto el intercambio de migrantes con el resto de centros urbanos de la Región Centro como una fuerte tendencia expulsora en el balance general. Si tomamos en cuenta las magnitudes de los flujos de salida, aunque han disminuido en el período hacia la mayoría de centros urbanos, se mantienen algunos importantes hacia centros seleccionados, como Pachuca, Toluca, Querétaro, y a ciudades chicas.

\section{Intercambios migratorios entre centros urbanos por rango tamańo}

Para analizar los intercambios de flujos migratorios entre todos los centros urbanos de la Región Centro se dividen dichos centros en cuatro categorías: zonas metropolitanas, ciudades medias, ciudades chicas y zonas rurales, en las cuales se incluye el resto del territorio. Con respecto a estas categorías, es interesante identificar aquellas ciudades más atractoras y las expulsoras por rango tamaño, a fin de poder señalar aquellos núcleos de mayores intercambios poblacionales que aparentemente han estado generando y/o perdiendo oportunidades productivas para la población.

En primer lugar, para las ZM más grandes, el análisis de los datos en el período 2010-2015 muestra que los saldos migratorios positivos de mayor magnitud en orden de importancia los registraron las ZM de Querétaro, Pachuca y Toluca; y para las ZM más chicas, destacan en el mismo sentido Cuautla y Tula como los polos atractores más importantes (tabla 6). Es de destacar que estas ZM atractoras reciben los más importantes flujos de entrada de las metrópolis más grandes, como la ZMCM y Puebla-Tlaxcala ante todo, lo que pone en evidencia la importancia de la migración metropolitana-metropolitana (figura 2). En segundo lugar son polos atractores de ciudades muy cercanas, sobre todo de sus propios estados. Un aspecto sobresaliente es que todas las ZM mayores de 500.000 habitantes son fuertes polos atractores de flujos de migrantes de alta magnitud provenientes de las ciudades pequeńas; es decir, una clara muestra de la importancia de la migración urbana-metropolitana.

El poder atractor de las cinco zonas metropolitanas mencionadas muestra una correlación directa con el incremento de empleo manufacturero en el período 1999 2014; ello a excepción de la ZM de Pachuca, que registra un ligero decremento en su empleo industrial. 
FIgURA 2 | Región Centro: flujos de entrada a las zonas metropolitanas más atractoras
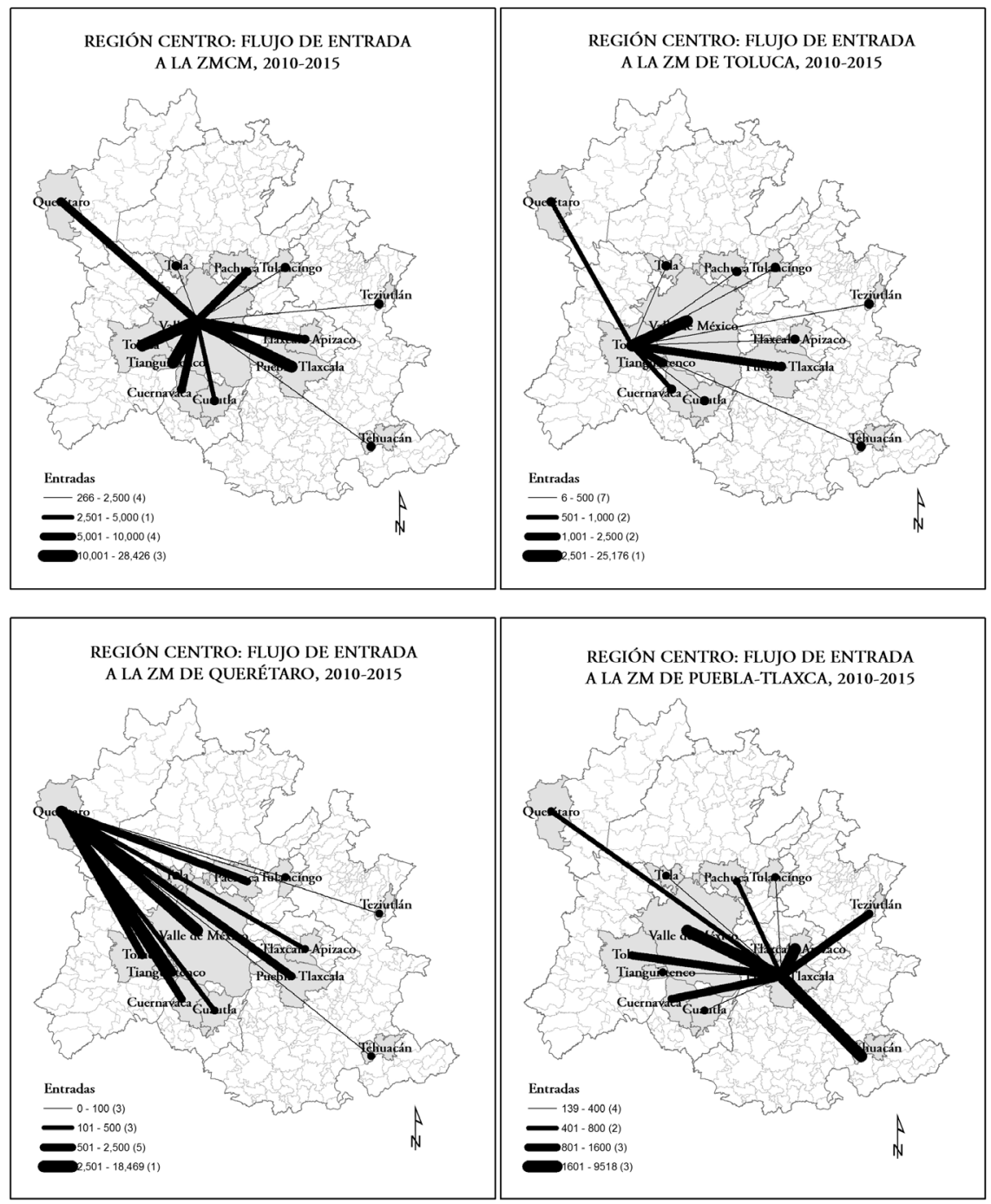

FUENTE CÁlCULOS PROPIOS CON DATOS DEL CENSO DE POBLACIÓN (2000) Y ENCUESTA INTERCENSAL, 20 I 5 . INSTITUTO NACIONAL DE ESTADÍSTICA Y GEOGRAFÍA (INEGI) 


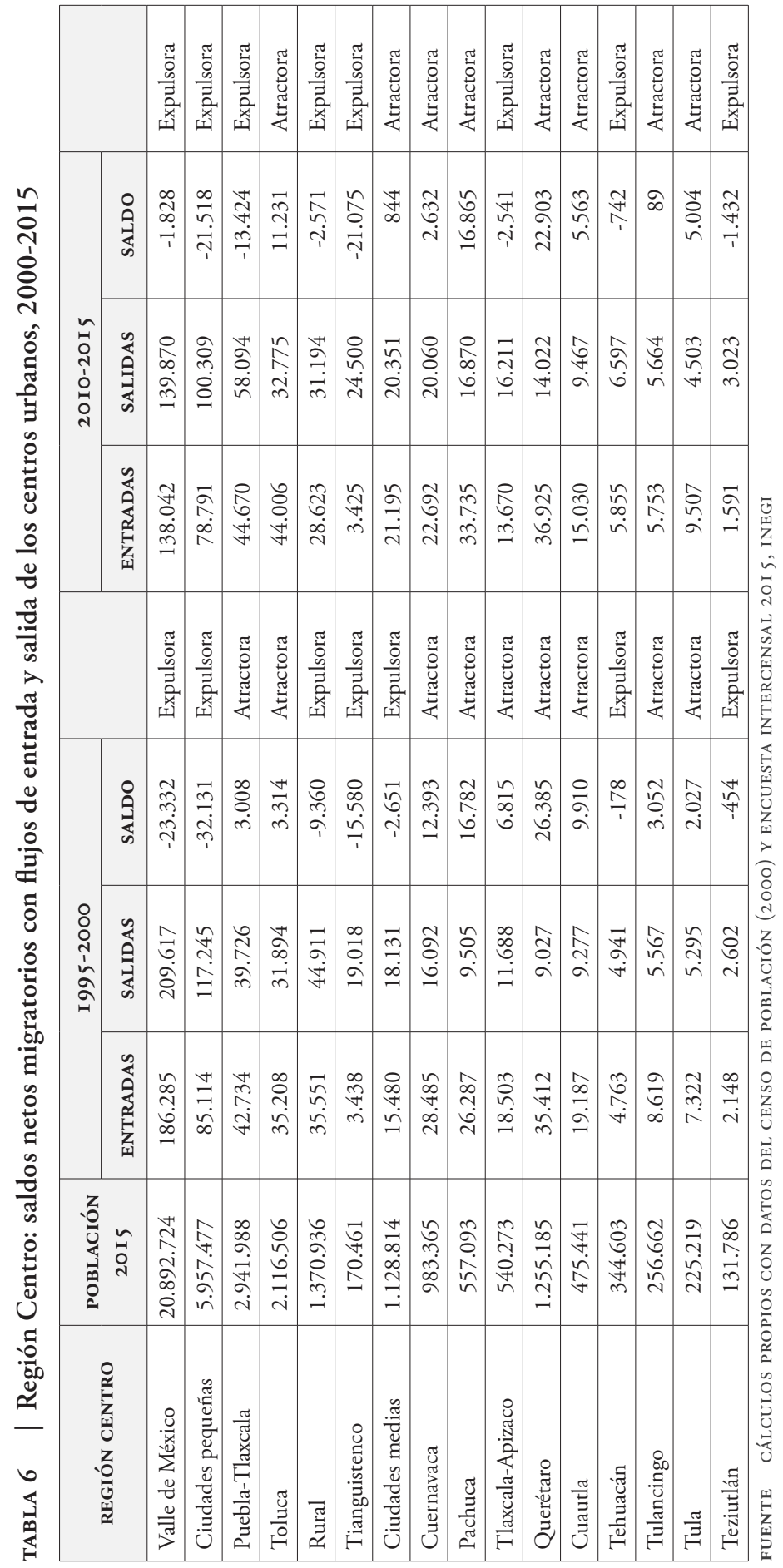


En segundo término, las ciudades medias presentan en general un saldo neto positivo en su balance de población migrante. Sin embargo, es necesario señalar dos particularidades: (i) respecto de la gran metrópoli de la Ciudad de México y de las ciudades pequeńas, las ciudades intermedias presentan un saldo neto positivo, lo cual muestra que son mayormente atractoras de población frente a los migrantes que se desplazan de la gran metrópoli y de las ciudades chicas; y (ii) respecto de la mayoría de las ZM, las ciudades medias expulsan más población de la que reciben, situación que también se repite en el intercambio con zonas rurales, hacia las cuales se desplaza más población de la que llega. Es decir, las ciudades medias son muy dinámicas en términos migratorios, porque a la vez que son fuertemente atractoras, también expulsan población de manera importante, con flujos de salida y entrada bastante similares: mientras en 2010-2015 sus flujos de entrada fueron de 21.195 migrantes, los de salida llegaron a 20.351 emigrantes. Junto con las ZM atractoras ya señaladas, las ciudades intermedias se han convertido en las principales protagonistas de una fuerte atracción de migrantes, que ya las identifican como los destinos alternativos de las grandes ciudades.

El tercer lugar, el caso de las ciudades pequeñas es particularmente preocupante para el desarrollo urbano-regional porque registran un saldo neto negativo en los dos períodos, y con altos flujos de salida. Es decir, aparecen como polos de expulsión de un alto número de población hacia la mayor parte de las ZM, incluyendo las ciudades medias. Destaca el hecho, sin embargo, de que con la ZM de la Ciudad de México tienen un saldo migratorio positivo, según el cual dicha metrópoli recibe más población de la que sale, aunque ambos flujos son muy altos. Así, se puede afirmar que presentan un alto dinamismo migratorio: su flujo de entrada en 2010-2015 fue de 78.791 migrantes, mientras que el de salida fue mucho más alto, con 100.309 emigrantes. Este carácter predominantemente expulsor -como ya se mencionó- da cuenta de sus deficientes condiciones de vida y de su escaso poder de retención de población. Hay que enfatizar que las ciudades pequeñas constituyen la categoría urbana con el más alto flujo de población migrante de entrada y de salida.

En el caso de las zonas rurales, y quizá como era de esperarse, existe un saldo neto negativo con todas las ZM, a excepción de la ZM de la Ciudad de México y de las ciudades medias. Es interesante este caso del intercambio migratorio con las zonas rurales, porque los datos tienden a mostrar que estas últimas se volvieron atractivas para la población migrante, o que incluso existen indicios de un proceso de contraurbanización. Pero es más probable que en el caso de las zonas rurales se hayan dado desplazamientos metropolitano-rurales y urbano-rurales que muestran un cambio de residencia muy cercano a las fronteras urbanas, pero con una localización rural; es decir, es difícil aceptar un supuesto atractivo de zonas rurales ante los evidentes rezagos que existen en ellas; más bien puede pensarse que existe una tendencia por parte de población urbana a buscar modalidades de residencia rural, atraída por un ámbito más tranquilo y menos congestionado. Rodríguez Vignoli (2016, p. 27) califica este posible proceso como una suerte de migración desde las ciudades al campo, sin que ello signifique un "retorno al campo" en el sentido integral de la palabra. No se puede dejar de señalar que también estas zonas tienen una alta dinámica migratoria, porque, por ejemplo, el número de migrantes es más 
alto que el que registran las ciudades medias; en el período 2010-2015 los flujos de entrada fueron de 28.623 migrantes, y los de salida, de 31.194. Esto es, no demasiado lejanos en magnitud.

Como último punto y atendiendo a los tipos de flujos migratorios y a la magnitud de todos ellos dentro de la RC (tabla 6), hay que enfatizar que es la migración metropolitana-metropolitana la que involucra el mayor número de migrantes que se desplazan entre zM (51,3\%); le sigue en importancia la migración urbana-metropolitana, con aquellos migrantes que se desplazan de centros urbanos chicos y medios a ZM (19,2\%); y en tercer lugar, la metropolitana-urbana, que incluye aquella población que se desplaza de todas las ZM a centros urbanos chicos y medianos $(15,2 \%)$. En el otro extremo, la tradicional migración rural-urbana $(2,2 \%)$ y la rural-metropolitana $(4,0 \%)$ han perdido importancia, considerando la magnitud del desplazamiento poblacional.

TABLA 7 Región Centro: tipos de migración interna por principales categorías urbanas y rurales, 2000-2015

\begin{tabular}{|l|c|c|}
\hline \multicolumn{1}{|c|}{ REGIÓN CENTRO } & 2000 & 20I5 \\
\hline Metropolitana-Metropolitana & 264.122 & 258.133 \\
\hline Urbana-Metropolitana & 120.218 & 96.706 \\
\hline Metropolitana-Urbana & 110.127 & 76.500 \\
\hline Rural-Metropolitana & 34.051 & 20.062 \\
\hline Metropolitana-Rural & 26.957 & 17.023 \\
\hline Urbana-Urbana & 6.666 & 12.354 \\
\hline Urbana-Rural & 8.594 & 11.600 \\
\hline Rural-Urbana & 10.860 & 11.132 \\
\hline
\end{tabular}

FUENTE CÁlCUlOS PROPIOS CON DATOS DEL CENSO DE POBLACIÓN (2000) Y ENCUESTA INTERCENSAL 2015 , INSTITUTO NACIONAL DE ESTADÍSTICA Y GEOGRAFÍA (INEGI)

\section{Conclusiones}

El análisis ha demostrado que la ZMvM aún constituye la gran ciudad de la Región Centro, pero, como varias grandes metrópolis de América Latina, ha mostrado una disminución en su ritmo de crecimiento en las últimas décadas. También presenta un poder de atracción mucho menor que antes sobre la población inmigrante, en gran medida vinculado al proceso de desindustrialización que experimenta y a la fragmentación y desconcentración de procesos productivos de la fase neoliberal. Y aunque la gran metrópoli es una de las grandes expulsoras de población migrante, sigue creciendo y recibiendo flujos migratorios secundarios, de menor magnitud, de prácticamente todas las categorías territoriales: zonas metropolitanas, ciudades medias y pequeñas, y zonas rurales. Con ello, también es claro que aún mantiene un poder de atracción de alta relevancia, considerando la magnitud de flujos que recibe. En otras palabras, los factores estructurales relacionados a una dinámica global, que impulsan un sector terciario avanzado y una multitud de actividades comerciales, revalorizan a la gran metrópoli e influyen en estas fuerzas centrípetas. 
De acuerdo con las teorías del ciclo del desarrollo urbano, como el de la urbanización diferencial, la gran metrópoli de la zмсM se encuentra en una fase avanzada de desconcentración urbana, donde las ciudades medias y las zonas metropolitanas crecen más rápidamente que la ciudad principal y son las zonas más atractivas para la población migrante; ello junto con algunas zonas rurales cercanas a centros urbanos que reciben influencias positivas. Pero, además, se ha configurado una región megalopolitana claramente policéntrica, con centros urbanos de diferentes jerarquías con intensos intercambios sociales y económicos, que es una expresión clara de una nueva forma de urbanización dominante. La nueva división funcional del trabajo y la redistribución de población al interior de este territorio han creado una nueva dinámica regional de fuertes interdependencias y movilidades, que son las que le dan su propia fortaleza a esta ciudad-región. Así, el rasgo característico de esta ciudad-región ya no es solo la presencia de una ciudad primaria como gran centro atractor, sino el desarrollo de una multitud de centros urbanos de varios tamaños interconectados, con una dinámica socioeconómica que caracteriza a cada uno y que los vuelve diferencialmente atractivos.

Pero, además, la ZMCM dentro de su ciudad-región es un ejemplo típico de cómo actualmente las grandes metrópolis son claras protagonistas en una nueva etapa de reversión de los flujos migratorios entre categorías urbanas y rurales; después de haber constituido el destino principal de los flujos rurales-urbanos hace poco más de treinta ańos, actualmente se han convertido en centros expulsores de migrantes, y son activas participantes en las migraciones metropolitanas-metropolitanas. No obstante, aún reciben flujos continuos de migrantes secundarios, lo que las ayuda a seguir teniendo un gran peso específico en el sistema urbano mexicano. Todo indica que tal peso se seguirá incrementando, aunque claramente a un ritmo más lento, por la transición que ha experimentado hacia una economía terciarizada y por la desconcentración de funciones económicas hacia su subsistema urbano inmediato.

La RC de México, que históricamente ha constituido la ciudad-región de la ZMCM y con ello su ámbito territorial de influencia inmediata, se ha convertido en un territorio de muy alto nivel de urbanización con la consolidación de varias zonas metropolitanas y ciudades de varios tamaños, que ya forman una estructura policéntrica donde los principales centros actúan como nodos de fuerte urbanización y atracción migratoria. En este caso particular, la generación de empleo aún es muy importante en esta región y nos muestra cómo la dinámica socioterritorial es selectiva y excluyente en varios sentidos: mientras la concentración del empleo manufacturero solo sucede en ZM seleccionadas, la mayoría de medianas dimensiones, la terciarización sí está generalizada en todos los centros urbanos, pero aun así, genera un mayor número de oportunidades para la población migrante en centros tanto urbanos como rurales, porque tiene más opciones en términos de destinos migratorios atractivos. Esta circunstancia de múltiples orígenes y destinos migratorios es un rasgo característico de las ciudades-región.

$\mathrm{El}$ análisis de los flujos migratorios al interior de la RC nos muestra también las desigualdades urbano-rurales características de un país en desarrollo como México y las debilidades para un desarrollo regional a fondo. Los intercambios migratorios muestran una fase avanzada de desconcentración urbana, donde la ciudad grande 
pierde dinámica demográfica y se da una consolidación de los centros urbanos medios, particularmente de las ZM menores y las ciudades intermedias. En este escenario, los flujos migratorios de mayores magnitudes son los que se dan entre las zonas metropolitanas, y entre las zonas urbanas y las zonas metropolitanas. Estas dos últimas categorías son actualmente los nodos de mayor atracción de migrantes, con los más altos saldos netos positivos; aunque es claro que solo es un grupo reducido de ellas, son las más atractivas, las más beneficiadas por la apertura comercial y la economía posindustrial. En el nivel más bajo de la jerarquía, las ciudades pequeñas y las zonas rurales carecen de suficientes atractivos para retener y atraer migrantes; las ciudades pequeńas muestran tener deficientes infraestructuras y opciones productivas, y ser los escalones más débiles de la jerarquía urbana. Cabe señalar que los saldos netos positivos de las zonas rurales con ciudades de varios tamańos muy probablemente se deben más a una relocalización de residencia de población urbana en zonas cercanas a ámbitos metropolitanos y urbanos que a un verdadero regreso al campo, según, por ejemplo, el argumento de la contraurbanización. Es decir, la falta de infraestructura, de servicios de alto nivel y de redes eficientes de comunicación en los niveles bajos de la jerarquía urbana y en las zonas rurales convierte a estos territorios en poco atractivos para el asentamiento de nuevos pobladores y constituye una deficiencia clara en el desarrollo regional. De cualquier manera, queda claro que los migrantes han diversificado sus destinos y siguen siendo uno de los principales motores de la urbanización en la ciudad-región.

\section{Referencias bibliográficas}

Aguilar, A. G. (2003). La megaurbanización en la Región Centro de México. Hacia un modelo de configuración territorial. En A. G. Aguilar (coord.). Urbanización, cambio tecnológico y costo social. El caso de la Región Centro de México (pp. 9-71). México D.F.: Instituto de Geografía, Universidad Nacional Autónoma de México (UNAM) / Miguel Angel Porrúa.

Aguilar, A. G. (2014). El reparto poblacional en el territorio. Tendencias recientes y desafíos futuros. En J. L. Ávila, H. Hernández Bringas, J. Narro Robles (eds.). Cambio demográfico y desarrollo de México (pp. 193-219). México, D.F.: Universidad Nacional Autónoma de México.

Aguilar, A. G. (2016). La región megalopolitana de la Ciudad de México. La morfología socioterritorial de la ciudad-región. En J. L. Ávila, H. Hernández Bringas \& M. López (coords.). Retos del cambio demográfico y epidemiológico de México (pp. 193-219). Colección de Población, Salud y Sociedad. Ciudad de México: Universidad Nacional Autónoma de México.

Aguilar A. G. \& Graizbord, B. (2002). Evolution and maturing of the Mexican urban system. En H. S. Geyer (ed.), International Handbook of Urban Systems. Studies of urbanization and migration in advanced and developing countries (pp. 419-454). Cheltenham, uK I Northampton, MA: Edward Elgar. 
Chávez Galindo, A. M. \& Guadarrama, J. (2004). La Región Central de México en transición: tendencias económicas y migratorias a finales del milenio. En A. G. Aguilar (coord.). Procesos metropolitanos y grandes ciudades. Dinámicas recientes en México y otros países (pp. 147-187). México D.F.: Instituto de Geografía, Universidad Nacional Autónoma de México (unam) / Miguel Angel Porrúa.

Chávez Galindo A. M., Rodríguez Vignoli J., Acuña M., Barquero J., Macadar D., Pinto da Cunha \& Sobrino J. (2016). Migración interna y cambios metropolitanos: ¿que está pasando en las grandes ciudades de América Latina? Revista Latinoamericana de Población, 10(8), 7-41. http://revistarelap.org/ojs/index.php/relap/article/view/137

Geyer H. S. (2002). An exploration in migration theory. En H. S. Geyer (ed.), International Handbook of Urban Systems. Studies of urbanization and migration in advanced and developing countries (pp. 19-37). Cheltenham, uK / Northampton, MA: Edward Elgar.

Geyer, H.S. \& Kontuly, T. (1996). A theoretical foundation for the concept of diferencial urbanization. En H. S. Geyer \& T. Kontuly (eds.), Differential urbanization: Integrating spatial models (pp. 290-308). Londres: Arnold.

Gottman, J. (1961). Megalopolis: The urbanized northeastern seaboard of the United State. Nueva York: Twentieth Century Fund.

Lang, R. \& Knox, O. K. (2009). The new metropolis: Rethinking megalopolis. Regional Studies, 43(6), 789-802. http://dx.doi.org/10.1080/00343400701654251

Morrill, R. (2006). Classical map revisited: The growth of megalopolis. The Professional Geographer [Association of American Geographers], 58(2), 155-160. http://dx.doi. org/10.1111/j.1467-9272.2006.00522.x

Nelles, J. (2013). Cooperation and capacity? Exploring the sources and limits of city-region governance partnerships. International Journal of Urban and Regional Research, 37(4), 1349-1367. http://dx.doi.org/10.1111/j.1468-2427.2012.01112.x

Olivera Lozano, G. \& Galindo Pérez, C. (2013). Dinámica económica y migración en el centro de México: impronta territorial de dos procesos convergentes. Economía, Sociedad y Territorio, 13(42), 381-430. http://www.redalyc.org/articulo.oa?id=11126608004

Parr, J. (2005). Perspectives on the city region. Regional Studies, 39(5), 555-566. http://dx.doi. org/10.1080/00343400500151798

Pérez Campuzano, E. (2006). Reestructuración urbano regional y nuevos derroteros de la migración en la Región Centro de México. El caso de la zMCM. Estudios Demográficos y Urbanos, 21(2), 331-367. http://dx.doi.org/10.24201/edu.v21i2.1252

Purcell, M. (2007). City-regions, neoliberal globalization and democracy: A research agenda. International Journal of Urban and Regional Research, 31(1), 197-206. http://dx.doi. org/10.1111/j.1468-2427.2007.00714.x

Regional Studies, 43(6), julio de 2009: The Futures of the City Region. http://www.tandfonline. $\mathrm{com} /$ toc/cres20/43/6?nav=tocList

Rodríguez Hernández, F. (2015). Contrastes del desarrollo socioeconómico en las zonas metropolitanas de Cuernavaca y Querétaro. Un análisis comparativo, 1990-2010. En A. G. Aguilar \& I. Escamilla (coords.), Segregación urbana y espacios de exclusión. Ejemplos de México y América Latina (pp. 431-462). México, D.F.: Instituto de Geografía, Universidad Nacional Autónoma de México (unAm) / Miguel Angel Porrúa. 
Rodríguez Vignoli, J. (2016). Urbanización, ciudades y migración en el siglo xxi: continuidad y cambio en América Latina. En M. E. Negrete (coords.), Urbanización y politica urbana en Iberoamérica. Experiencias, análisis y reflexiones (pp. 19-59). Ciudad de México: El Colegio de México.

Scott, A. J. (2008). Resurgent metropolis: Economy, society and urbanization in an interconnected world. International Journal of Urban and Regional Research, 32(3), 548-564. http://dx.doi.org/10.1111/j.1468-2427.2008.00795.x

Scott, A. J. (ed.). (2001). Global city-regions: trends, theory, policy. Oxford: Oxford University Press.

Secretaría de Desarrollo Social (Sedesol), Consejo Nacional de Población (Conapo) \& Instituto Nacional de Estadística y Geografía (Inegi). (2010). Delimitación de las Zonas Metropolitanas de México, 2010. México, D.F.: Sedesol / Conapo / Inegi. http://www. conapo.gob.mx/es/CONAPO/Zonas_metropolitanas_2010

Sobrino, L. J. (2010). Migración interna en México durante el siglo XX. México, D.F.: Consejo Nacional de Población (Conapo).

Sobrino, L. J. (2016). Dinámica y distribución territorial de la población en México. En M. E. Negrete (coord.), Urbanización y política urbana en Iberoamérica. Experiencias, análisis y reflexiones (pp. 61-105). Ciudad de México: El Colegio de México.

Vicino, T. J., Hanlon, B. \& Short, J. R. (2007). Megalopolis 50 years on: The transformation of a city region. International Journal of Urban and Regional Research, 31(2), 344-367. http://dx.doi.org/10.1111/j.1468-2427.2007.00728.x

Wheeler S. (2009). Regions, megaregions, and sustainability. Regional Studies, 43(6), 863-876. http://dx.doi.org/10.1080/00343400701861344 